\title{
Laws of the unconditioned reflex in the rabbit nictitating membrane preparation
}

\author{
BEVERLY MARSHALL-GOODELL \\ University of Iowa, lowa City, Iowa \\ E. JAMES KEHOE \\ University of New South Wales, Kensington, Australia \\ and \\ I. GORMEZANO \\ University of Iowa, Iowa City, Iowa
}

\begin{abstract}
The unconditioned response (UR) of the rabbit's nictitating membrane (NM) was examined as a function of the intensity and duration of electrotactile and airpuff unconditioned stimuli (USs). For both USs, increases in US intensity produced increases in UR likelihood and amplitude, and decreases in onset latency. Increases in US duration had similar but smaller effects on the UR. The peak latency of the UR was also examined, but it proved to be highly variable. The data were analyzed by using progressively larger NM movements to define a UR. The lower criteria of $0.125,0.250$, and $0.500 \mathrm{~mm}$ produced virtually identical results. The more stringent criteria of $0.750,1$, and $2 \mathrm{~mm}$ produced decreases in the observed UR likelihood, increases in apparent UR amplitude, and increases in apparent peak latency.
\end{abstract}

The purpose of the present experiment was to delineate the laws of the unconditioned reflex in the rabbit nictitating membrane (NM) preparation. Specifically, we examined the effects of the intensity and duration of electrotactile and corneal airpuff unconditioned stimuli (USs) on the likelihood, amplitude, and time course of the NM unconditioned response (UR). As part of this examination, we also determined whether the reflex laws varied as a function of the amplitude criterion for defining a UR.

The unconditioned reflex in the rabbit NM preparation is increasingly a point of departure for neurobehavioral research. First, a behavioral characterization of the unconditioned reflex is essential to identifying its neural pathways and distinguishing them from those subserving the NM conditioned reflex (e.g., Berthier \& Moore, 1983; Nowak, 1991; Nowak \& Gormezano, 1990; Schreurs, 1987, 1988; Thompson, Berger, \& Madden, 1983). Second, examination of the unconditioned reflex is providing insights into sensory processing and nonassociative behavioral changes, particularly as a consequence of drug administration (e.g., Gormezano \& Harvey, 1980; Schindler, Gormezano, \& Harvey, 1985). Third, the uncondi-

This research was supported by National Institute of Drug Abuse Grant DA0-5075-02, National Science Foundation grants, the University of Iowa Foundation (through the generous contributions of D. Boatman, H. Gormezano, S. L. Nusser, and W. G. Nusser), and Australian Research Council Grant AC89322441. The authors wish to acknowledge with appreciation the assistance of Kim Kirkpatrick-Steger in the analysis of the data. Correspondence concerning this article should be sent to I. Gormezano, Department of Psychology-SSH, University of Iowa, Iowa City, IA 52242. tioned reflex is subject to modifications by a conditioned stimulus (CS) during its early pairings with the US (e.g., Harvey, Gormezano, \& Cool-Hauser, 1985; Ison \& Leonard, 1971; Weisz \& LoTurco, 1988; Weisz \& Walts, 1990; Young, Cegavaske, \& Thompson, 1976). Fourth, the unconditioned reflex is essential to the acquisition of conditioned responses (CRs) to a CS (see Gormezano, Kehoe, \& Marshall, 1983).

Despite the significance of the unconditioned reflex in its own right and in CR acquisition, there have been few systematic characterizations of the unconditioned reflex in the NM preparation. In drug studies, US intensity effects on UR likelihood have been delineated to reveal monotonically increasing functions for both an electrotactile US (e.g., Gormezano \& Harvey, 1980) and airpuff US (e.g., Schindler et al., 1985). Recently, Schreurs and Alkon (1990) manipulated the intensity and duration of an electrotactile US and examined their effects on several measures of the UR. As US intensity and US duration were increased, the UR's likelihood, amplitude, and duration increased, whereas the onset latency and peak latency decreased. The present study was conducted to provide an even more comprehensive delineation of the unconditioned reflex in the rabbit NM preparation by (1) using both an electrotactile US and an airpuff US, (2) extending the range of US intensities and US durations to larger values than those used by Schreurs and Alkon (1990), (3) examining the impact of altering the criterion for defining URs on their detection and the measurement of other features, and (4) using a greater number of animals per experimental group, thereby achieving greater statistical power to detect any differences. 
With regard to the UR criterion, the data were analyzed by using progressively more stringent criteria applied to the minimum extension of the NM that counted as a UR. In the previous studies of the unconditioned reflex, a $0.500-\mathrm{mm}$ criterion yielded orderly effects. However, it remained to be determined whether the $0.500-\mathrm{mm}$ criterion maximized sensitivity to the effects of the US parameters while minimizing the spurious detection of random movements of the NM. For example, the use of lower criteria could produce greater sensitivity or could equally produce an increased likelihood of spurious responses. As a corollary to identifying the optimal criterion, alternative criteria were examined to determine the tolerance of the reflex laws to different criteria.

\section{METHOD}

\section{Subjects}

The subjects were 144 naive male and female albino rabbits (Oryctolagus cuniculus), each 70-80 days old and weighing approximately $2 \mathrm{~kg}$ on arrival. The rabbits were housed individually and had free access to food and water. Consistent with their rearing conditions, the animals were kept in constant light.

\section{Apparatus}

The apparatus and recording procedure for the nictitating membrane (NM) response were patterned after those of Gormezano (1966) and are detailed by Gormezano and Gibbs (1988). The US was either (1) a $60-\mathrm{Hz}$, AC current delivered via 9-mm Autoclip wound clips positioned $10 \mathrm{~mm}$ apart and $15 \mathrm{~mm}$ posterior to the caudal canthus of the right eye or (2) an airpuff delivered through a 16-gauge hypodermic tube directed at a right angle to the center of the cornea of the right eye at a distance of $4.5 \mathrm{~mm}$ from its surface. To monitor movements of the NM, a small wire hook was attached to a nylon loop sutured in the NM of the rabbit's right eye. The other end of the hook was attached through a universal joint to a crank that operated a photoelectric transducer (Gormezano \& Gibbs, 1988). The signal from the transducer was sampled every 2 msec during trial periods and subjected to analog/digital (A/D) conversion. The sequence and timing of US presentations, the A/D conversion, and response analysis were accomplished by an Apple II/FIRST system containing interfaces and software described by Scandrett and Gormezano (1980).

\section{Procedure}

All rabbits had 1 day of preparation, 1 day of adaptation, and 1 day of testing. On the preparation day, hair posterior to the rabbit's right eye was shaved, and a 2-mm loop of nylon (6-O Ethicon) was sutured into the right NM. On the adaptation day, the rabbits were placed in the conditioning apparatus for $60 \mathrm{~min}$, but the US was not presented.

Following adaptation, the rabbits were assigned randomly to one of six groups $(n=24)$. For three groups, the US was the electrotactile stimulus, and its duration was manipulated between groups across the values of 50,100 , and $200 \mathrm{msec}$. Within each group, the US intensity was varied across the values of $0,0.5 ., 1,2$, and $4 \mathrm{~mA}$. For the remaining three groups, the airpuff US was used, and its duration was either 50,100 , or $200 \mathrm{msec}$. Within each group, the US intensity varied across $0,5,10,20$, and 40 psi. For all groups, the testing session contained a total of 50 trials, 10 of each US intensity. The sequence of trials was randomized, with the restriction that 1 trial of each US intensity was presented in each block of 5 trials. The mean intertrial interval (ITI) was $60 \mathrm{sec}$ (range: 50-70 sec).

\section{UR Measurements}

The UR was defined in terms of the amplitude of any NM extension within 1,250 msec following US onset. On zero-intensity trials, "URs" were defined during the same interval as that used on trials containing a US. In the case of the airpuff, US onset was defined as the time at which the airpuff reached the surface of the cornea.

To determine the consequences of using different amplitude criteria for the NM response, the data were analyzed with the use of six criteria-namely, $0.125,0.250,0.500,0.750,1$, and $2 \mathrm{~mm}$. Thus, for each criterion, any NM extension that equaled or exceeded the designated value was counted as a UR. Each UR, so defined, was also analyzed for its maximum amplitude, onset latency, and peak latency. The onset latency was defined as the time point at which the UR first departed from the baseline by $0.0625 \mathrm{~mm}$. This value $(1 / 16$ th $\mathrm{mm})$ is the smallest movement that can be resolved by our A/D device. The peak latency was the first time point at which the UR reached its maximum amplitude (for a detailed description of the response-scoring algorithm, see Marshall-Goodell, Schreurs, \& Gormezano, 1982; Scandrett \& Gormezano, 1980).

\section{RESULTS}

\section{Electrotactile US}

Likelihood. The top row of panels in Figure 1 shows the percentage of URs as a function of US intensity for each NM response criterion. There is a separate panel for each US duration. Inspection of the panels reveals that, for each criterion, UR likelihood was a direct function of US intensity. For the zero intensity (no US), random NM movements that were counted as "URs" were rare $(M<1 \%)$. For the $0.5-\mathrm{mA}$ intensity, a small number of URs appeared; for the stronger intensities, the likelihood of URs rose dramatically. Averaging across all other variables, the means for the $0.5-, 1-, 2-$, and 4-mA intensities were $6 \%, 39 \%, 70 \%$, and $79 \%$, respectively.

US duration had a moderate effect on UR likelihood, which was apparent only under the stronger intensities. For example, under the $0.5-\mathrm{mA}$ intensity, the means were $5 \%, 9 \%$, and $6 \%$ for the US durations of 50,100 , and $200 \mathrm{msec}$, respectively. In contrast, under the $2-\mathrm{mA}$ intensity, there was a rise in UR frequency across US durations. Specifically, the means were $52 \%, 95 \%$, and $90 \%$, respectively.

With regard to NM response criteria of $0.125,0.250$, and $0.500 \mathrm{~mm}$, the likelihood functions for detecting the UR completely overlapped at all US intensities and durations. For those criteria, the overall means were $54 \%$, $53 \%$, and $53 \%$, respectively. For the more stringent criteria of $0.750,1$, and $2 \mathrm{~mm}$, the observed likelihood of URs progressively dropped; the overall means were $49 \%$, $46 \%$, and $36 \%$, respectively. Despite the drop in the detection of URs, the reliability of the percentage measure remained high and constant. Specifically, the standard error around the means for the six criteria ranged from $2.5 \%$ to $2.6 \%$, based on a total of 288 observations aggregated across groups, subjects, and intensities. It might be thought that the use of lower criteria would cause an increase in false alarms, that is to say, the spurious detection of URs would be expected to be most obvious when measured on zero-intensity trials. In fact, the number of 

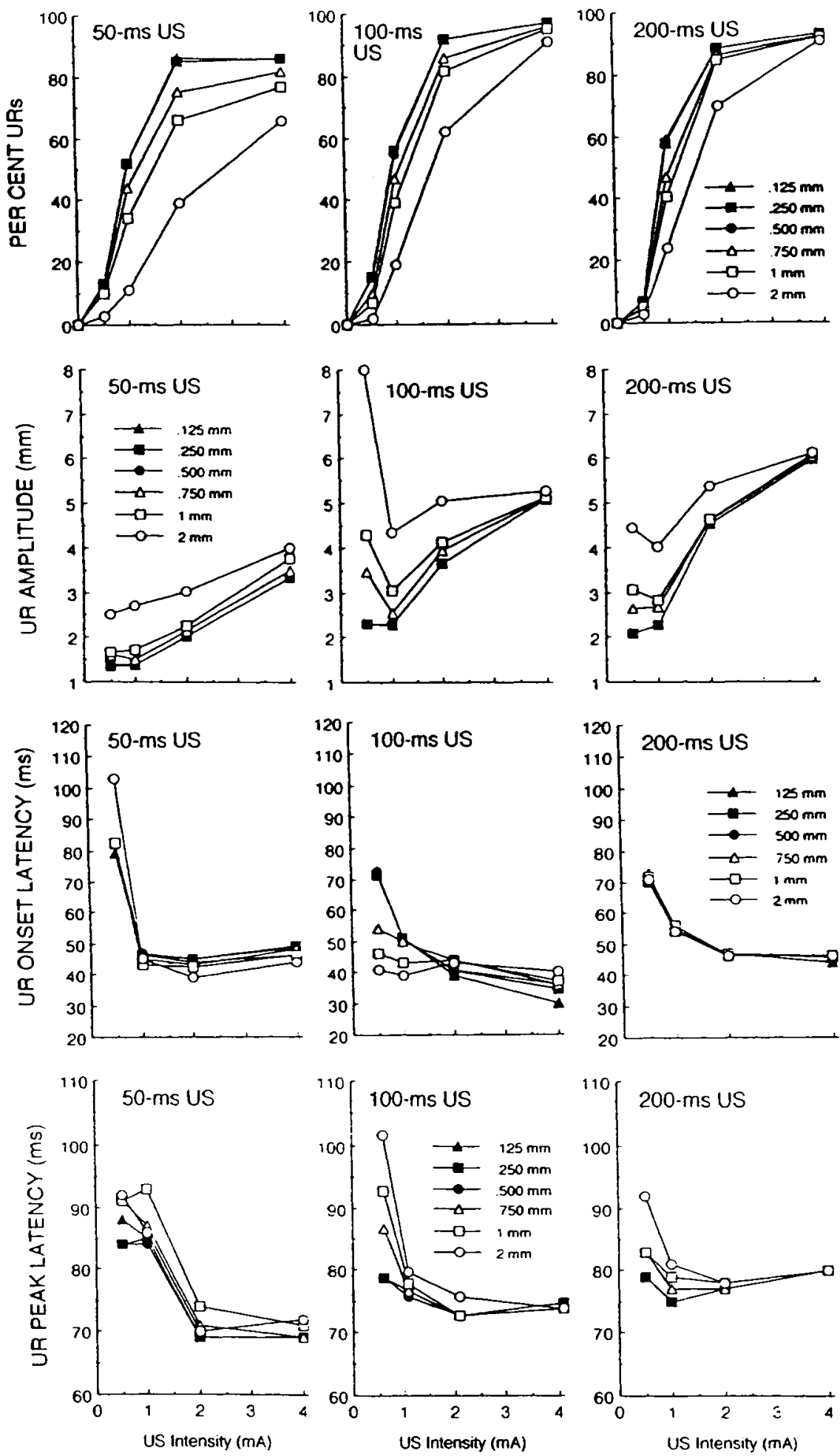

Figure 1. UR measures as a function of the electrotactile US intensity. There is a separate panel for each US duration, and each panel contains six curves, one for each UR criterion. The UR measures in order from top to bottom are percent URs, amplitude, onset latency, and peak latency. 
random NM movements counted as URs was negligible for all criteria. In particular, the mean UR likelihood on zero-intensity trials for the criteria of $0.125,0.250,0.500$, $0.750,1$, and $2 \mathrm{~mm}$ was $0.7 \%, 0.7 \%, 0.7 \%, 0.7 \%$, $0.6 \%$, and $0.3 \%$, respectively.

Amplitude. The second row of panels in Figure 1 shows the maximum amplitude of URs arranged in the same manner as the likelihood measure in the top panels. There are no data for the zero-value of the US because so few spontaneous NM extensions exceeded even the 0.125 -mm criterion. With the exception of the $100-\mathrm{msec}$, $0.5-\mathrm{mA}$ US, the UR amplitude rose as a direct function of US intensity and US duration. The overall means were $2.6,2.5,3.6$, and $4.8 \mathrm{~mm}$ for US intensities of 0.500 , 1,2 , and $4 \mathrm{~mA}$, respectively, and $2.3,3.9$, and $4.88 \mathrm{~mm}$ for US durations of 50,100, and $200 \mathrm{msec}$, respectively. Raising the criterion raised the apparent amplitude and flattened the effects of the intensity and duration variables. Averaged across those variables, the mean UR amplitudes for the criteria of $0.125,0.250,0.500,0.750,1$, and $2 \mathrm{~mm}$ were, $3.4,3.4,3.4,3.7,3.9$, and $4.7 \mathrm{~mm}$, respectively, all with standard errors of $0.2 \mathrm{~mm}$. The increase in amplitude across the criteria was preordained, because increasing the criterion progressively excluded smaller NM movements from contributing to the mean amplitude. In addition, the mean for the $100-\mathrm{msec}, 0.5-\mathrm{mA}$ US became very large as the criterion was raised. The inflation in the mean occurred because there were few URs elicited by that intensity, but among them, there were some large URs that distorted the mean.

Onset latency. Inspection of the third row of panels in Figure 1 reveals that UR onset latency decreased as US intensity increased. The overall mean onset latencies for 0.5-, 1-, 2-, and 4-mA intensities were 58, 48, 42, and $40 \mathrm{msec}$, respectively. In contrast to the strong effect of US intensity, the effects of US duration appeared small and unsystematic: The 50-, 100-, and 200-msec durations produced mean onset latencies of 47,40 , and $46 \mathrm{msec}$, respectively. Changing the criterion tended to produce small decreases in the mean onset latency: Overall, the mean onset latencies for the criteria of 0.125 , $0.250,0.500,0.750,1$, and $2 \mathrm{~mm}$ were $44,45,45,44$, 43 , and $42 \mathrm{msec}$, respectively, all with standard errors of $1 \mathrm{msec}$.

Peak latency. The fourth row of panels in Figure 1 reveals that peak latency decreased across US intensities in a fashion that roughly paralleled UR onset latency. Specifically, the overall mean peak latencies for $0.500-, 1-$, $2-$, and 4-mA intensities were $311,271,230$, and $242 \mathrm{msec}$, respectively. Regarding US duration, the $50-, 100-$, and 200-msec US durations produced mean peak latencies of 248,259 , and $278 \mathrm{msec}$, respectively. Unlike onset latency, peak latencies tended to increase slightly and become more variable as the criterion was raised, particularly at the weaker intensities and longer durations. Overall, the mean peak latencies for the criteria of $0.125,0.250,0.500,0.750,1$, and $2 \mathrm{~mm}$ were 246 , $243,240,252,269$, and $261 \mathrm{msec}$, respectively. The cor- responding standard errors were $8,8,8,9,11$, and 11 msec, respectively.

Statistical analyses. An analysis of variance (ANOVA) using a Type I error of .05 was conducted for each UR measure. In agreement with the features of the UR as described above, US intensity and UR criteria had large effects on all the measures, and US intensity had smaller, less consistent effects. Specifically, US intensity had a significant main effect on UR likelihood $[F(3,198)=$ $222.81, p<.001]$, amplitude $[F(3,198)=50.59, p<$ $.001]$, onset latency $[F(3,198)=57.44, p<.001]$, and peak latency $[F(3,198)=5.35, p<.01]$. Similarly, varying the criterion had a significant main effect on UR likelihood $[F(5,330)=97.88, p<.001]$, amplitude $[F(5,330)=345.48, p<.001]$, onset latency $[F(5,330)=12.63, p<.001]$, and peak latency $[F(5,330)=8.54, p<.001]$. US duration had a main effect on only UR likelihood $[F(2,66)=10.84, p<$ $.001]$ and amplitude $[F(2,66)=10.99, p<.001]$. However, there were significant interactions of duration $x$ intensity for onset latency $[F(6,198)=15.26, p<.001]$ and peak latency $[F(6,198)=9.19, p<.001]$. There was also a duration $x$ intensity interaction for UR likelihood $[F(6,198)=7.30, p<.001]$. Finally, there were three-way interactions of criterion $\times$ duration $\times$ intensity for the measures of amplitude, onset latency, and peak latency [smallest $F(30,990)=10.14, p<.001$ ]

\section{Airpuff US}

Figure 2 shows the UR measurements for the airpuff US. The figure is arranged in exactly the same manner as is Figure 1. Inspection of Figure 2 reveals that the results resemble those of the electrotactile US. As will be detailed below, there was only one exception: Mean peak latency increased, rather than decreased, with increases in the US intensity.

Likelihood. As is shown in the top row of panels of Figure 2, UR likelihood was a direct function of US intensity. For nonzero intensities, the overall means for the $5-, 10-, 20-$, and 40 -psi intensities were $56 \%, 65 \%, 74 \%$, and $76 \%$, respectively. US duration also had a modest, but positive, effect: the overall means for the 50-, 100-, and 200 -msec durations were $64 \%, 67 \%$, and $73 \%$, respectively. With regard to criteria, the likelihood of detecting a UR decreased as criteria were increased over the $0.500-\mathrm{mm}$ value. The overall means were $74 \%, 74 \%$, $74 \%, 70 \%, 66 \%$, and $52 \%$, for criteria of $0.125,0.250$, $0.500,0.750,1$, and $2 \mathrm{~mm}$, respectively, all with standard errors of $2 \%$. With regard to zero-intensity trials, the likelihood of detecting a spurious UR was negligible for all criteria. The means for the progressively more stringent criteria were $2.0 \%, 2.0 \%, 2.0 \%, 1.3 \%, 1.0 \%$, and $1.0 \%$, respectively.

Amplitude. UR amplitude rose as a direct function of US intensity. The overall means were $2.8,3.2,3.9$, and $4.4 \mathrm{~mm}$ for the $5,10,20$, and $40 \mathrm{psi}$, respectively. The effects of US duration were small: The amplitude increased by approximately $1 \mathrm{~mm}$ across the three dura- 

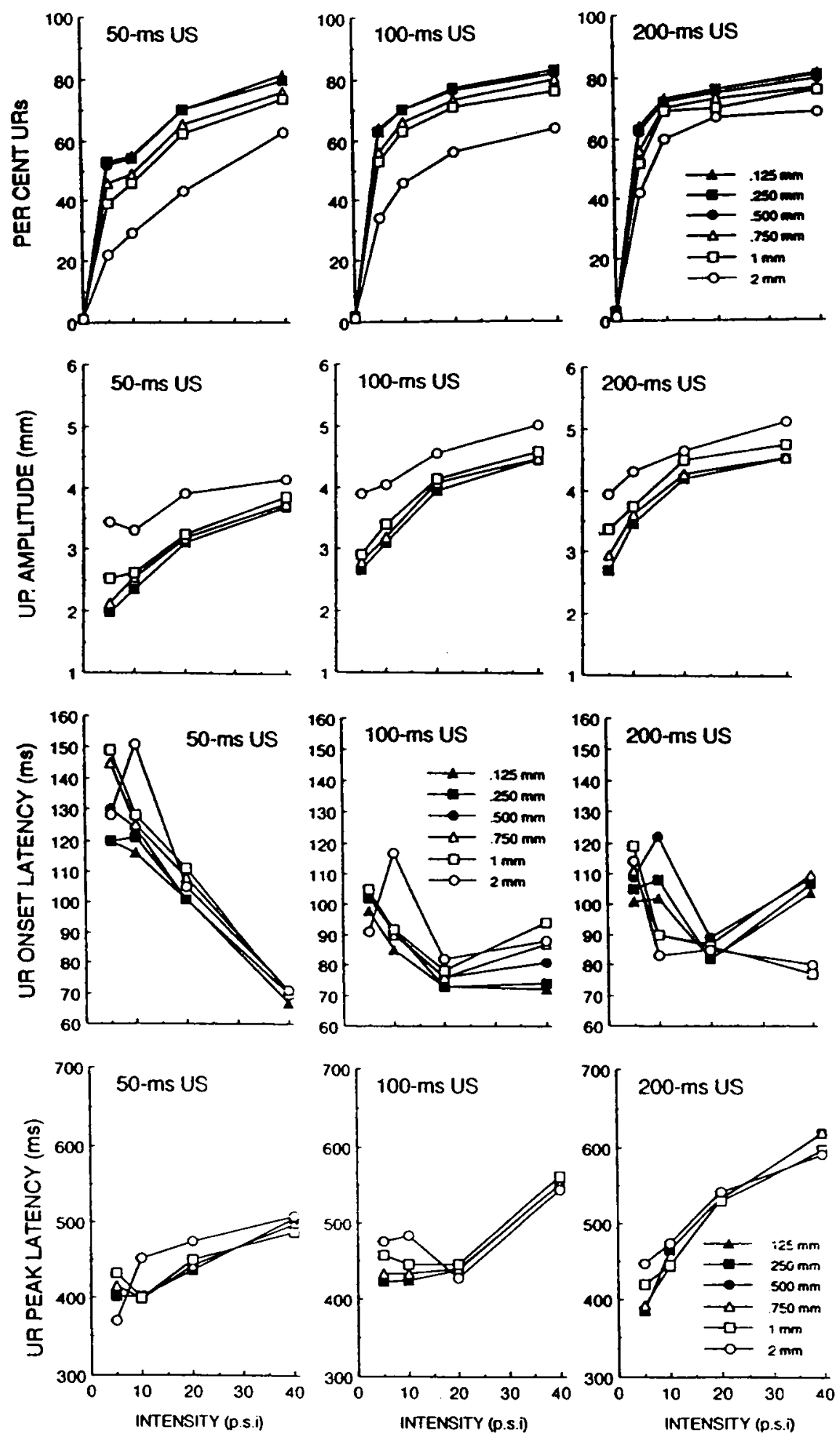

Figure 2. UR measures as a function of the airpuff US intensity. There is a separate panel for each US duration, and each panel contains six curves, one for each UR criterion. The UR measures in order from top to bottom are percent URs, amplitude, onset latency, and peak latency. 
tions. Successively raising the amplitude criterion from 0.125 to $2 \mathrm{~mm}$ yielded an increase in the overall mean amplitudes from 3.4 to $4.2 \mathrm{~mm}$, all with standard errors of $0.1 \mathrm{~mm}$.

Onset latency. UR onset latency decreased as US intensity increased. Overall, the mean onset latencies for $5,10,20$, and $40 \mathrm{psi}$ were $114,107,89$, and $84 \mathrm{msec}$, respectively. There were some variations in the size of the US intensity effects across US durations and UR criteria. For the 50-msec US duration and all amplitude criteria, the mean onset latencies declined from $135 \mathrm{msec}$ at 5 psi to $70 \mathrm{msec}$ at $40 \mathrm{psi}$. For the 100 - and $200-\mathrm{msec}$ US durations, there appeared to be greater variability across criteria. Nevertheless, for the two longer durations, there was a modest decline in the mean onset latencies from $105 \mathrm{msec}$ at 5 psi to $90 \mathrm{msec}$ at 40 psi. Overall, raising the criterion produced a modest increase in the mean onset latency from 94 to $98 \mathrm{msec}$. The standard errors were relatively constant, falling between 5 and $6 \mathrm{msec}$.

Peak latency. The peak latency diverged from onset latency. Although onset latency decreased as airpuff intensity rose, peak latency showed increases. For 5, 10, 20 , and 40 psi, the mean peak latencies were 415,436 , 473 , and 555 msec, respectively. The increase in peak latencies across intensities became more pronounced as US duration increased. Across the NM response criteria, the mean peak latencies rose from 466 to $486 \mathrm{msec}$, with standard errors between 12 and $13 \mathrm{msec}$.

Statistical analyses. The ANOVAs conducted for the effects of the airpuff US confirmed the observed features of the reflex portrayed in Figure 2. Specifically, US intensity had a significant main effect on UR likelihood $[F(3,198)=22.22, p<.001]$, amplitude $[F(3,198)=$ $52.22, p<.001]$, onset latency $[F(3,198)=4.69, p<$ $.01]$, and peak latency $[F(3,198)=5.94, p<.001]$. Similarly, increasing the NM response criterion had a significant main effect on UR likelihood $[F(5,330)=83.79$, $p<.001]$, amplitude $[F(5,330)=548.69, p<.001]$, and peak latency $[F(5,330)=8.54, p<.001]$. On the other hand, US duration had neither main nor any interaction effects with the intensity factor. There were significant three-way interactions of criterion $x$ duration $x$ intensity for the amplitude, onset latency, and peak latency [smallest $F(30,990)=3.56, p<.001$ ]

\section{Latency Distributions}

To provide a more detailed description of the time course of the URs, Figure 3 shows the frequency distributions for onset latencies and peak latencies for both electrotactile and airpuff USs. Each panel shows a separate distribution for each US intensity. Each distribution represents an aggregate across all 72 subjects. The distributions are based on those NM movements that met the conventionally used $0.500-\mathrm{mm}$ criterion. The ordinate of each scale has been adjusted to expose the shape of each distribution.

Inspection of the onset latencies reveals that, for both types of US, the bulk of URs were initiated within
$100 \mathrm{msec}$ after US onset. However, the electrotactile US appeared to produce onset latencies that were shorter and more tightly distributed than those produced by the airpuff US. As is seen in the analysis of the means, the UR onset latencies for the two weaker intensities appeared to be somewhat longer than they were for the two stronger intensities.

The distributions of peak latency showed more variability. The UR peaks to the electrotactile US were distributed over an interval of between 100 and $400 \mathrm{msec}$. The more intense USs tended to produce broader distributions with two modes, one around $150 \mathrm{msec}$ and the other around $250 \mathrm{msec}$. The two modes resulted from the aggregation of the distributions across US durations. Inspection of the separate distributions for the 50-, 100-, and 200-msec durations (not shown) revealed that they had distinct modes around 120,150 , and $250 \mathrm{msec}$, respectively.

The peak latencies for the airpuff US were even more broadly distributed than they were for the electrotactile US. The tails of the distributions extended out to $1,000 \mathrm{msec}$ after US onset. The more intense airpuffs, especially at 40 psi, produced a nearly square distribution of between 150 and $500 \mathrm{msec}$ after the US onset. There were no discernible effects of US duration on those distributions.

\section{DISCUSSION}

The major findings of the present experiment were as follows: First, increases in US intensity produced increases in likelihood, increases in amplitude, and decreases in onset latency. Second, US duration had similar, but more modest, effects on the UR measures. Specifically, increases in US duration produced increases in UR likelihood and UR amplitude. Third, the ordinal relationships in these reflex laws were relatively constant across variations in the UR criterion. Nevertheless, increases in the criterion above $0.500 \mathrm{~mm}$ tended to flatten the functional relationships, as well as to produce overall decreases in the observed likelihood, overall increases in apparent amplitude, and overall increases in apparent peak latency.

Among the UR measures, likelihood, amplitude, and onset latency produced a coherent picture. Generally, the URs become more probable, larger, and faster as US intensity and US duration increased. Peak latency was the exception to this picture. Peak latency was a highly variable measure-it was less sensitive than were the other measures to US intensity and US duration. Furthermore, mean peak latency did not fully cohere with the other measures. In particular, for the airpuff US, peak latency increased rather than decreased as US intensity increased.

The results of the present study agree with previous findings by Gormezano and his associates (e.g., Gormezano \& Harvey, 1980; Schindler et al., 1985) and by Schreurs and Alkon (1990). Both the present results and those of Schreurs and Alkon revealed large effects of US 

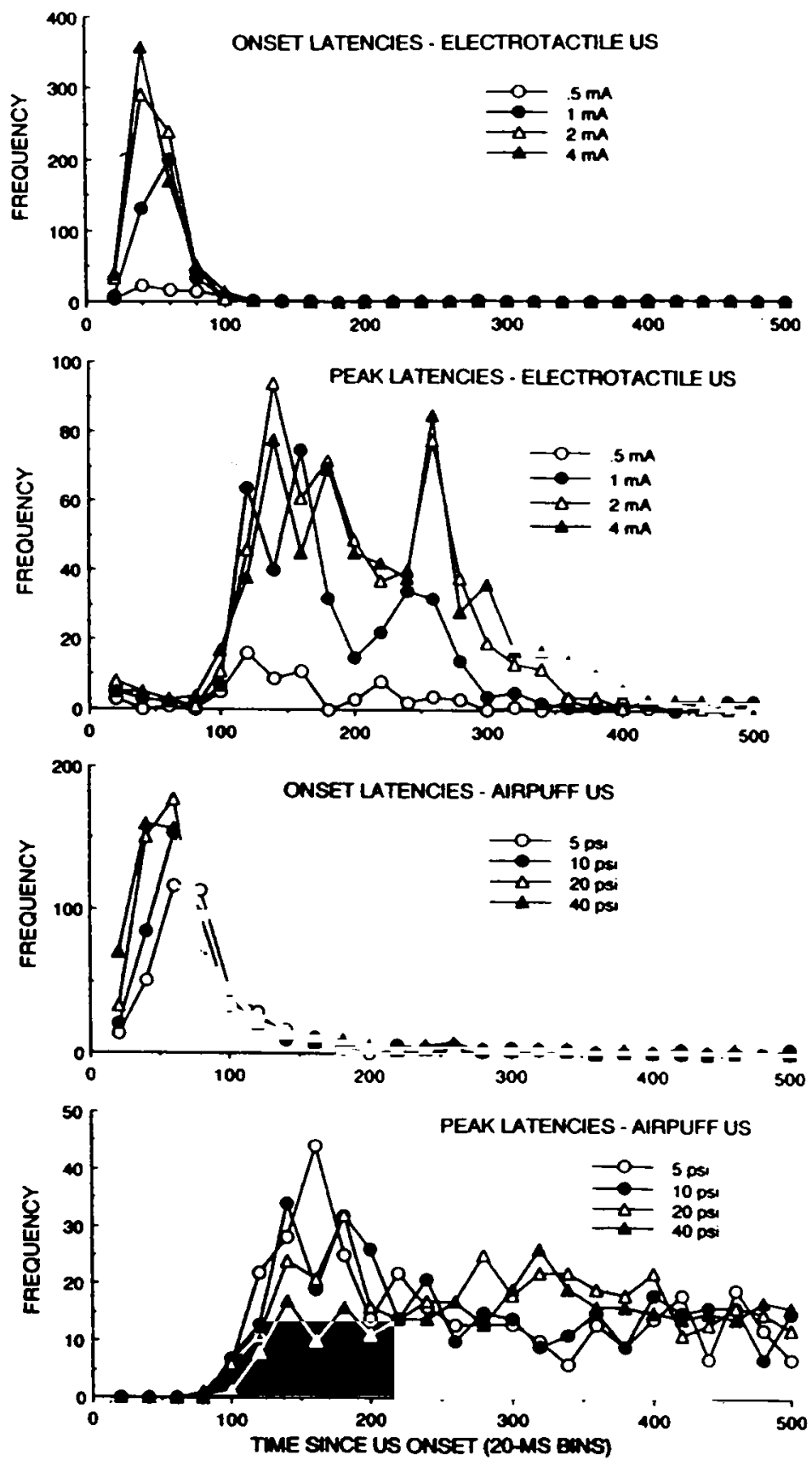

Figure 3. Frequency polygons for onset latencies and peak latencies for both electrotactile and airpuff USs. Each panel shows a separate distribution for each US intensity. Each distribution represents an aggregate across all 72 subjects that received each type of US. The distributions are based on those NM movements that met the $0.500-\mathrm{mm}$ criterion. The ordinate of each scale has been adjusted to expose the shape of each distribution.

intensity and smaller effects of US duration. However, for identical US values, the electrotactile US in the present study produced fewer URs with smaller amplitudes and longer latencies than those reported by Schreurs and Alkon. This divergence in UR measures may arise from differences in the positions of the stimulating electrodes around the eye. We placed both electrodes posterior to the caudal canthus, whereas Schreurs and Alkon used a circumorhital placement, in which only one electrode was placed posterior to the caudal canthus and the other electrode was placed below the eye. The resulting differences in the UR measures parallel previous findings in NM conditioning regarding electrode positions. For example, Salafia, Martino, Cloutman, and Romano (1979) found 
that paraorbital placement produced slower CR acquisition than did circumorbital placement.

In the present experiment, it was not possible to conduct a statistical comparison between the effects of the electrotactile and airpuff USs, because their intensities were on different physical scales. However, on the basis of informal comparisons, it seems safe to conclude that they follow parallel reflex laws. Both USs yielded similar effects for US intensity, US duration, and UR criterion variations. There were some quantitative differences in the time course of their respective URs, as revealed in their onset latencies and peak latencies. The electrotactile US generally produced more tightly packed distributions with mean onset latencies around $44 \mathrm{msec}$ and mean peak latencies around $251 \mathrm{msec}$. In contrast, the airpuff US produced more widely dispersed URs, with mean onset latencies around $98 \mathrm{msec}$ and mean peak latencies around $471 \mathrm{msec}$. The only apparent functional divergence between the two USs was in the opposite effect of their respective intensities on mean peak latency. However, little weight can be placed on this apparent divergence, because peak latency was in all respects the most variable UR measure.

The unconditioned reflex laws for the electrotactile US largely parallel those obtained for CR acquisition as a function of US intensity and US duration. Specifically, NM conditioning studies have shown that US intensity has large and robust positive effects on CR likelihood (Ashton, Bitgood, \& Moore, 1969; Smith, 1968), whereas US duration has had smaller, more variable, positive effects on CR likelihood (Ashton et al., 1969; Tait, Kehoe, \& Gormezano, 1983). In agreement with the positive effects of US intensity on UR amplitude and UR onset latency, Smith's (1968) conditioning study yielded similar effects of US intensity on the corresponding measures of the CR. However, CR peak latency has proved to be a highly sensitive measure in a way that could not have been anticipated from the UR peak latency. Unlike the highly variable UR peak latency, the CR peak latency tends to be tightly distributed just after the point of US delivery. Moreover, the CR peak latency is very sensitive to conditioning manipulations such as the CS-US interval (Gormezano et al., 1983; Smith, 1968) and interruptions in the CS (Kehoe \& Napier, 1991).

It has been conventional to use a criterion of $0.500 \mathrm{~mm}$ for both URs and CRs in the NM preparation. The present results reveal that $0.500-\mathrm{mm}$ has been, in fact, a suitable criterion for UR definition. On the one hand, anything greater both diminishes the likelihood of detecting a UR and diminishes the apparent effect of variables as robust as US intensity. On the other hand, the smaller criteria do not produce any noticeable gain in sensitivity. However, caution has to be exercised in viewing the criteria between $0.125 \mathrm{~mm}$ and $0.500 \mathrm{~mm}$ as interchangeable. Although they yielded virtually identical functions in the present study, it must be kept in mind that the smaller criteria may be more susceptible to any additional noise in the NM resting baseline that might arise from experimental interventions such as drugs, lesions, or brain stimulation. In the face of additional noise, lower criteria would disproportionately produce the spurious counting of small, random movements as URs.

Even more caution must be exercised in extrapolating any conclusions regarding the UR criterion to the CR criterion. During the early studies in which the NM preparation was used, the $0.500-\mathrm{mm}$ criterion was adopted because it represented the smallest movement that could be reliably detected by observers from oscillograph records. Subsequently, the $0.500-\mathrm{mm}$ criterion was used in calibrating the current computer system to match human judgments (Marshall-Goodell et al., 1982). It might be tempting to assume that the current computer apparatus and algorithms could reliably use a smaller criterion than could a human observer. Such an assumption however would be mistaken. Although a computer system is immune to "noise" in judgments arising within the human observer, a computer system is just as susceptible as the human to the noise arising from the subject's behavior, transducer apparatus, and experimental treatment. Moreover, in the case of CR acquisition, a computer system, as with a human observer, cannot avoid the increases in response amplitude over training, which are accompanied by systematic changes in variability.

The empirical consequences for CR detection for different amplitude criteria remain largely to be determined. However, Nordholm, Lavond, and Thompson (1991) have begun this determination. They used criteria of 0.100 and $0.500 \mathrm{~mm}$ for $\mathrm{NM}$ movements during a tone CS to analyze the data from several groups of rabbits. It was found that the $0.100-\mathrm{mm}$ criterion yielded a high likelihood of spuriously counting small movements as responses. For example, during initial unpaired exposure to the CS and an airpuff US, the mean likelihood of counting a small movement as a response reached as high as $21 \%$ under the $0.100-\mathrm{mm}$ criterion. In contrast, the 0.500 mm criterion yielded no spurious counts; the obtained likelihood of a response never exceeded 1\%. During subsequent CS-US pairings, the smaller criterion inflated the apparent level of $C R$ acquisition. For example, in the group that showed the most CR acquisition, the 0.100$\mathrm{mm}$ criterion yielded a level of detected CRs that reached $75 \%$, whereas the $0.500-\mathrm{mm}$ criterion yielded a level that reached only $30 \%$ CRs.

A comparison of the present findings with Nordholm et al.'s (1991) findings reveal the dangers of extrapolating from UR measurements to CR measurements. In our findings, there was no discernible effect of using criteria of 0.125 and $0.500 \mathrm{~mm}$ on the detection of URs following the US. Moreover, neither of those two criteria produced the detection of any spurious URs during periods without the US. In contrast, Nordholm et al. found that the $0.100-\mathrm{mm}$ criterion, compared with the $0.500-\mathrm{mm}$ criterion, dramatically increased the likelihood of counting small NM movements as responses during unpaired and paired CS-US trials.

The results of the present experiment reveal that the NM unconditioned reflex displays orderly changes as a function of US intensity and US duration. Moreover, these 
reflex laws were robust in two respects. First, they were similar for the two types of US, electrotactile and airpuff. Second, they were relatively tolerant to different amplitude criteria for counting a NM movement as a response. The regularity and robustness in the unconditioned reflex laws provide a firm foundation for using the rabbit NM response as a model preparation for neurobehavioral studies of the unconditioned reflex in its own right. However, there is evidence to suggest that airpuff USs may elicit NM URs that are mediated by a more restricted pathway than that of the electrotactile USs (Marek, McMaster, Gormezano, \& Harvey, 1984). Specifically, NM URs elicited by airpuff and electrotactile USs are both primarily mediated by the retractor bulbi muscle (via the VI nerve), but electrotactile USs also involve contraction of the obicularis oculi muscle (via the VII nerve), which then squeezes the NM over the cornea. Accordingly, in choosing the physiologically appropriate US, the airpuff's elicitation of URs, with its more restricted pathway, would presumably make it the more effective US for the study of the neural substrates of learning.

Finally, the parallel reflex laws of electrotactile and airpuff USs for US intensity would lead to the expectation of parallel effects on CRs. However, given that electrotactile and airpuff USs were on different scales, to determine whether or not they yield comparable effects on CR acquisition would require psychophysically equating electrotactile and airpuff intensity and subsequently determining their effects on CR acquisition. The psychophysical equivalence for electrotactile and airpuff intensities could be specified with any dependent variable measure of the URs. However, UR frequency and amplitude would be the most likely candidates, since they have been repeatedly demonstrated to reveal a strong direct relationship to $\mathrm{CR}$ acquisition.

\section{REFERENCES}

Ashton, A. B., Bitgood, S. C., \& Moore, J. W. (1969). Auditory differential conditioning of the rabbit nictitating membrane response: III. Effects of US shock intensity and duration. Psychonomic Science, 15, 127-128.

Berthier, N. E., Moore, J. W. (1983). The nictitating membrane response: An electrophysiological study of the abducens nerve and nucleus and the accessory abducens nucleus in rabbit. Brain Research, 258, 201-210.

Gormezano, I. (1966). Classical conditioning. In J. B. Sidowski (Ed.), Experimental methods and instrumentation in psychology (pp. 385420). New York: McGraw-Hill.

Gormezano, I., \& GibBs, C. M. (1988). Transduction of the rabbit's nictitating membrane response. Behavior Research Methods, Instruments, \& Computers, 20, 18-21.

Gormezano, I., Harvey, J. A. (1980). Sensory and associative effects of LSD in classical conditioning of rabbit (Oryctolagus cuniculus) nictitating membrane response. Journal of Comparative \& Physiological Psychology, 94, 641-649.

Gormezano, I., Kehoe, E. J., Marshall, B. S. (1983). Twenty years of classical conditioning research with the rabbit. In J. M. Sprague \& A. N. Epstein (Eds.), Progress in psychobiology and physiological psychology (pp. 197-275). New York: Academic Press.

Harvey, J. A., Gormezano, I., * Cool-Hauser, V. A. (1985). Relationship between heterosynaptic reflex facilitation and acquisition of the nictitating membrane response in control and scopolamine-injected rabbits. Joumal of Neuroscience, 5, 596-602.

IsON, J. R., LEONARD, D. W. (1971). Effects of auditory stimuli on the amplitude of the nictitating membrane reflex of the rabbit (Oryccolagus cuniculus). Joumal of Comparative \& Physiological Psychology, 75, 157-164.

KEHOE, E. J., NAPIER, R. M. (1991). In the blink of an eye: Real time stimulus factors in delay and trace conditioning of the rabbit's nictitating membrane response. Quarterly Joumal of Experimental Psychology, 43B, 257-277.

Marek, G. J., McMaster, S. E., Gormezano, I., * Harvey, J. A. (1984). The role of the accessory abducens nucleus in the rabbit nictitating membrane response. Brain Research, 299, 215-229.

Marshall-Goodell, B., Schreurs, B. G., Gormezano, I. (1982). Ruler vs. the Apple II/FIRST system analysis of analog signals in classical conditioning. Behavior Research Methods \& Instrumentation, 14, 519-525.

Nordholm, A. F., LAvond, D. G., Thompson, R. F. (1991). Are eyeblink responses to tone in the decerebrate, decerebellate rabbit conditioned responses? Behavioural Brain Research, 44, 27-34.

Nowak, A. J. (1991). Electrical brain stimulation of the brain stem, midbrain, and thalamic structures as a condirioned stimulus during classical conditioning and reflex modification of the rabbit's NMR Unpublished doctoral dissertation, University of lowa, Iowa City.

NowAK, A. J., \& Gormezano, I. (1990). Electrical stimulation of brainstem nuclei: Elicitation, modification, and conditioning of the rabbit nictitating membrane response. Behavioral Neuroscience, 104, 4-10.

Salafia, W. R., Martino, L. J., Cloutman, K., Romano, A G. (1979). Unconditional-stimulus locus and interstimulus-interval shif in rabbit (Oryctolagus cuniculus) nictitating membrane conditioning. Pavlovian Journal of Biological Science, 14, 64-71.

SCANDRETt, J., Gormezano, I. (1980). Microprocessor control and A/D data acquisition in classical conditioning. Behavior Research Methods \& Instrumentation, 12, 120-125.

SChindler, C. W., Gormezano, I., \& Harvey, J. A. (1985). Effects of morphine and LSD on the classically conditioned nictitating membrane response. Pharmacology, Biochemistry \& Behavior, 22, 41-46.

SChreurs, B. G. (1987). Parameters and sites of brainstem stimulation capable of eliciting the rabbit nictitating membrane response. $B e-$ havioural Brain Research, 25, 155-160.

Schreurs, B. G. (1988). Stimulation of the spinal trigeminal supports classical conditioning of the rabbit's nictitating membrane response. Behavioral Neuroscience, 102, 163-172.

SCHREURS, B. G., ALKON, D. L. (1990). US-US conditioning of the rabbit's nictitating membrane response: Emergence of a conditioned response without alpha conditioning. Psychobiology, 18, 312-320.

SMITH, M. C. (1968). CS-US interval and US intensity in classical conditioning of the rabbit's nictitating membrane response. Joumal of Comparative \& Physiological Psychology, 66, 679-687.

Tait, R. W., Kehoe, E. J., Gormezano, I. (1983). Effects of US duration on classical conditioning of the rabbit's nictitating membrane response. Joumal of Experimental Psychology: Animal Behavior Processes, 9, 91-101.

Thompson, R. F., Berger, T. W., \& MAdDEN, J. (1983). Cellular processes of learning and memory in the mammalian central nervous system. Annual Review of Neuroscience, 6, 447-491.

WeISz, D. J., LoTurCo, J. J. (1988). Reflex facilitation of the nictitating membrane response remains after cerebellar lesions. Behavioral Neuroscience, 102, 203-209.

WeISz, D. [J.], WALTS, C. (1990). Reflex facilitation of the rabbit NMR by an auditory stimulus as a function of ISI. Behavioral Neuroscience, 104, 11-20.

Young, R. A., Cegavaske, C. F., Thompson, R. F. (1976). Toneinduced changes in excitability of abducens motoneurons and of the reflex path of the nictitating membrane response in rabbit (Oryctolagus cuniculus). Journal of Comparative \& Physiological Psychology, 90, 424-434.

(Manuscript received January 14, 1992 revision accepted for publication July 16, 1992.) 